\title{
Current Account Reversals Triggered by Large Exchange Rate Movements
}

\section{Nikolas A. Müller-Plantenberg*}

Universidad Autónoma de Madrid

nikolas.mullerpl@uam.es

\begin{abstract}
Japan's long-lasting current account surplus as well as Germany's temporary surplus during the 1980s are the two largest current account surpluses the world has witnessed. Remarkably, net exports were rising in both countries despite the large overall appreciation of the Japanese yen and the considerable strength of the German mark. This paper shows that the real exchange rate still mattered for the export performance of these economies. It applies a Markov-switching time series model to the current accounts of both countries, in which the transition probabilities depend on the level of the real exchange rate. It finds that both countries' current accounts, while overall rising, experienced several setbacks and subsequent recoveries, with clear turning-points. It further demonstrates that current account reversals were triggered by the real exchange rate appreciating, or depreciating, too strongly.

* I thank Danny Quah and Wojciech S. Maliszewski for helpful suggestions. I am also grateful for comments I received from seminar participants at the International Financial Stability Programme at the CEP (LSE), the 8th Spring Meeting of Young Economists in Leuven, Belgium, and the 59th European Meeting of the Econometric Society in Madrid.
\end{abstract}


Keywords: current account reversals, exchange rate fluctuations, time-varying transition probabilities.

JEL Classification: F32, C32, C11, C15

\section{INTRODUCTION}

Japan's current account surplus, the ever-largest in the world, has been on the rise for more than two decades in spite of a sustained real appreciation of the yen during this period (see figure 1). Similarly, Germany experienced a boom in exports throughout the 1980s, just until the German unification, despite the considerable strength of the German mark. Japan's and Germany's current account surpluses far exceed in value the surplus of other any other country at any time (see figure 2).

Figure 1. Japanese current account and exchange rate. Japanese current account (left scale, in trillions of yen, transformed from biannual to quarterly frequency using a natural cubic spline smooth) and nominal effective exchange rate (right scale, in logarithms), period from 1968Q1 to 1999Q4. Source: Economic Outlook (OECD), IFS (IMF)

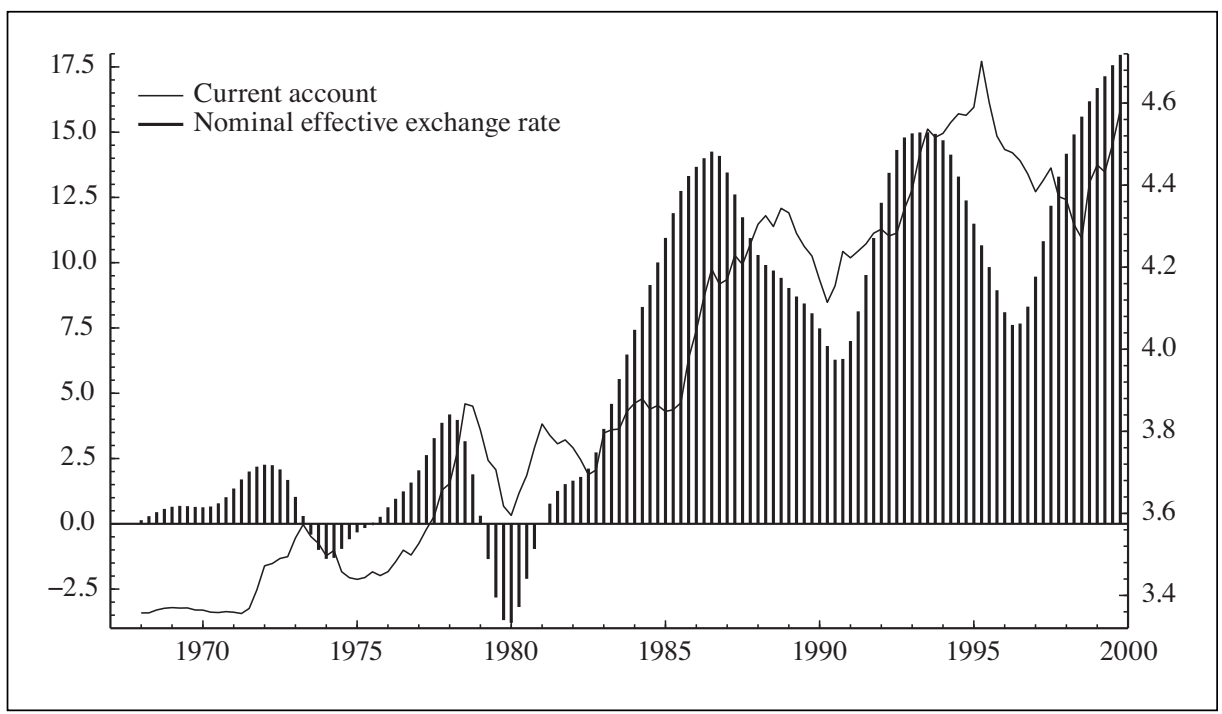


Whatever made these two countries so competitive, it was not the exchange rate. From 1980Q1 to 1995Q1, the yen for instance appreciated by 56 percent in real terms (based on WPI-based price indices). Despite considerable fluctuations, the currency has remained very strong in recent years. Although the German mark appreciated substantially in nominal terms in the 1980s, the currency did not experience an equally impressive real appreciation as the yen. However, being at the time the anchor currency of the EMS, the German mark was widely perceived as a hard currency and as such not really conducive to Germany's strong export growth.

Figure 2. Large current account surpluses. Current account balances of countries with large current account surpluses (in billions of US dollar). Countries are selected and ordered according to the highest current account balance they have achieved in any single quarter in the period from 1977Q1 to 2001Q3. Source: International Financial Statistics (IMF)
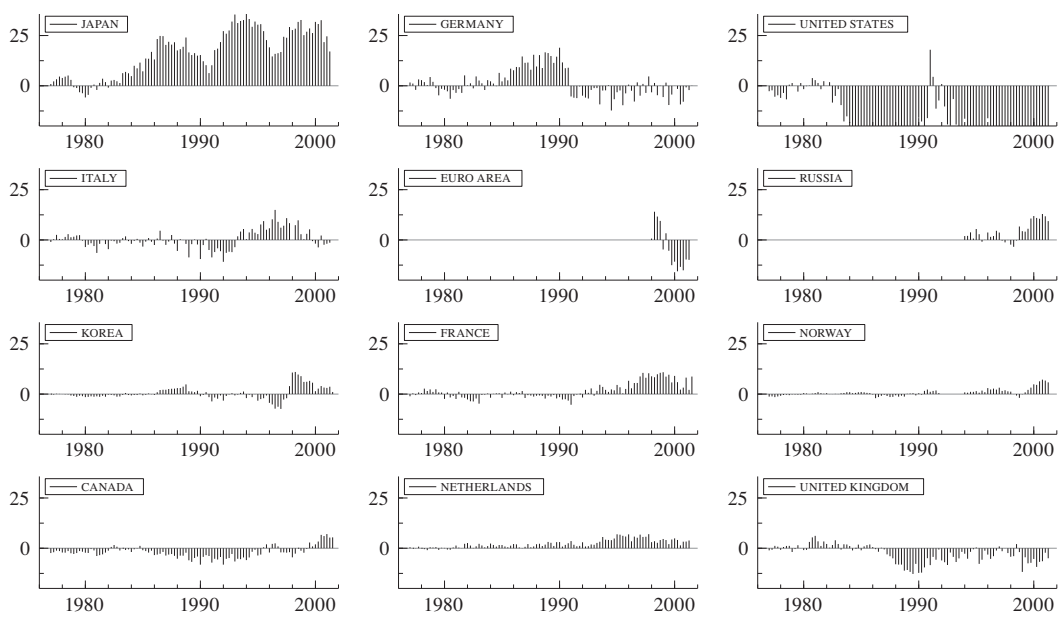

This paper argues that the external performance of both countries was nevertheless affected by the exchange rate. Based on the empirical evidence, it is noted that export booms were subject to various setbacks that often lasted for several quarters or even years. Almost all of these setbacks, however, were preceded by, or occurred simultaneously with, strong exchange rate appreciations around the same time. Subsequent recoveries usually took place at times when the exchange rate had become more competitive again. 
Theory suggests that if exchange rates are volatile and costs of firms to adjust their export capacities and to enter foreign markets are sunk, large exchange rate movements are needed to trigger trade balance reversals. This result can be derived from real options theory (Dixit and Pindyck, 1994) and is closely linked to what Baldwin and Krugman called the beachhead effect in international trade (Baldwin, 1988, Baldwin and Krugman, 1989). However, whereas the theoretical idea is not new, little progress has been made on the empirical side. Baldwin and Krugman (1989) already pointed to the difficulties of attempts to empirically test their theory:

Here the problem is one of both technique and data. The dynamic effects we model are not captured by the usual econometric assumptions that behavior can be represented by continuous functions and a fixed structure of leads and lags. Thus, unconventional techniques, and perhaps a reliance on case-study-like evidence, may be necessary.

This paper analyses a Markov-switching time series model of the current account designed to capture the recurrent swings of this economic variable. There are two regimes, one in which the current account is heading upwards, another one in which it is declining. A crucial feature of the setup is that the transition probabilities are time-varying and allowed to depend on the exchange rate.

To analyse the model, the paper employs a Bayesian estimation strategy. For inference on the parameter posteriors and on the unobserved regimes, the simulation tool of Gibbs sampling is used. The Gibbs sampler - a method that is based on the idea of alternate conditional simulations - turns the complex conditional structure of the model to its advantage.

Of particular economic interest is the question to what extent regime changes are explained by movements of the exchange rate. To assess this question, the paper applies the methodology of Kim and Nelson (1998), which those authors used to study the duration dependence of business cycles. The idea is to apply a variable selection procedure to a latent variable regression that determines the regime that the current account is in. The specific variable selection method adopted is that proposed by Geweke (1996) in the context of Bayesian regression.

The topic of this paper is related to the empirical literature on the sensitivity of trade flows to exchange rate changes. A typical finding in this literature is that import and export demand elasticities are rather low and that the Marshall-Lerner condition does not hold. Some authors have called the link between the real exchange rate and the real trade balance altogether into question (see Rose, 1990). Nevertheless, a 
consensus seems to exist that devaluations do improve the trade balance of countries although the effect may take a long time due to the J-curve effect.

Of interest in our context is the study of Kim (1998) who fails to detect an effect of exchange rate variations on Germany's international competitiveness when using aggregate trade data from 1982 to 1991 (he finds, however, some effects for disaggregated data). Sawyer and Sprinkle (1997) offer a survey on this type of literature for Japan. They explicitly only consider studies that do not produce estimates with the «wrong» sign; even so, they find that imports are quite insensitive to changes in the exchange rate on average while exports appear to respond somewhat more strongly to the exchange rate.

The paper is organized as follows. Section 2 examines the time series evidence of both countries. Section 3 introduces the empirical model. Section 4 reports on the data used and discusses the choice of priors. Section 5 presents the main empirical findings. Section 6 provides conclusions.

\section{External Performance of J Japan and Germany}

This paper looks at two countries that experienced remarkable export booms in the 1980s and 1990s. Figure 2 gives us an idea of just how large Japan's and Germany's export surpluses were in US-dollar terms compared to those of other countries. Japan's current account balance recorded the world's ever-largest surplus during the past two and a half decades, and it was mirrored to a large extent by the unprecedented current account deficit run by the United States. Germany also achieved a considerable surplus in the 1980 s which then turned into deficit due to the German reunification. The objective of this paper is to understand the role that exchange rates have played in the evolution of these large external imbalances.

\subsection{Japan}

Consider figures 1 and 3, which plot the time series of Japan's current account and of its nominal and real effective exchange rates during the 1970s, 1980s and 1990s. Note that the real exchange rate is defined in this paper as the foreign-currency price of the domestic currency. It is evident from the graphs that the Japanese current account did not rise in a stable fashion; instead, it was subject to repeated setbacks with subsequent recoveries. Overall, the current account exhibited several large swings, all of which lasted for several years. 
The other remarkable feature of the data is that all large turnabouts of the current account were preceded by large movements in the exchange rate. This is true for the export booms setting off in 1974, 1980, 1990 and 1996 with the aid of a depreciated yen. It is also true for the episodes starting in 1973, 1978, 1986 and 1993 when the current account began to weaken following large appreciations of the yen.

\subsection{Germany}

Consider now figure 4 which shows the corresponding time series for Germany. Apparently, the German experience is quite similar to that of Japan. Germany's current account was also going through several upward and downward swings. And as in Japan, the temporary strength of the domestic currency, or its temporary weakness, appears to have triggered many of the turnabouts in net exports. The effect is particularly noticeable in 1978, 1981, 1983, 1984, 1986 and to a lesser extent in 1987. Note that Germany's current account balance alternated more frequently between booms and declines than that of Japan.

Figure 3. Japanese current account and exchange rates (1980s and 1990s). Japanese current account (left scale, in trillions of yen) and nominal and real effective exchange rates (right scale, in logarithms), period from 1977Q1 to 2001Q1. Source: International Financial Statistics (IMF)

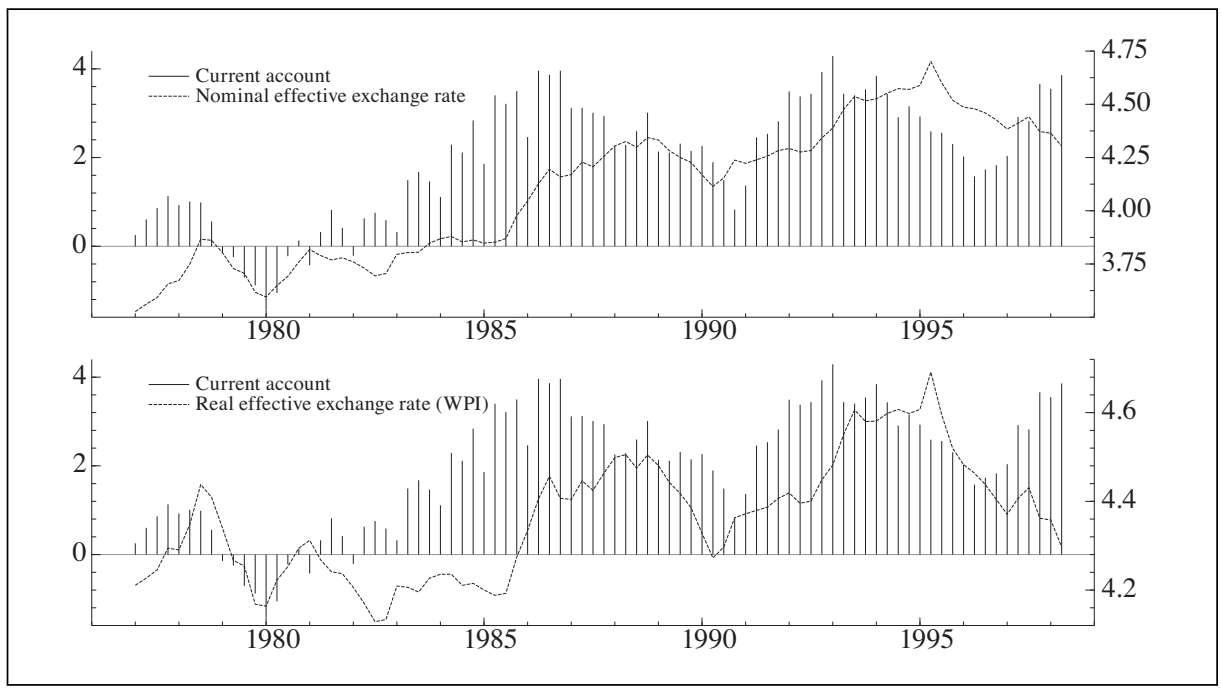




\subsection{Current account adjustment under uncertainty}

Before embarking on an empirical analysis, this may be a good moment to think about the underlying economic reasons for the observed empirical regularities in both the Japanese and German data. There are in fact a number of plausible stories that can explain why it is the trend, rather than the level, of the current account that adjusts to exchange rate shifts. In both countries considered in this paper, the current account movements were largely mirroring the performance of the trade balance in the periods considered. One possible explanation therefore is that import demand in Japan and Germany as well as in their trading partners' economies was adjusting relatively slowly to changes in the real exchange rate. An important reason for this could be the well-documented low rate of pass-through from exchange rate movements to import prices.

Figure 4. German current account and nominal and real exchange rates (1980s). German current account (centered, yearly moving average, left scale, in million DM) and nominal and real effective exchange rate (monthly data, 1980s). Source: Economic Outlook (OECD),

\section{IFS (IMF)}

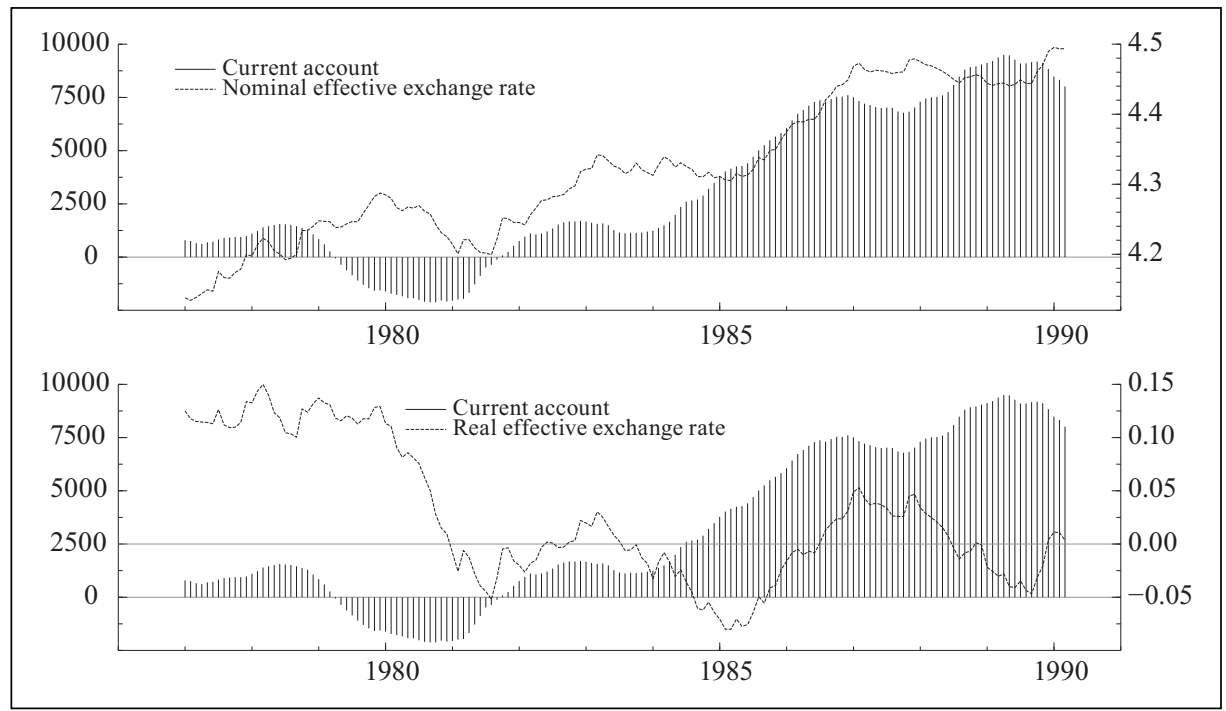

However, a potentially even more compelling economic argument would focus on the supply side rather than the demand side and be based on ideas from real options 
theory (see for instance Dixit and Pindyck, 1994). As noted above, the fluctuations of the current account have been rather large in Japan and Germany. Achieving higher external surpluses, and likewise reducing them, always involves considerable capacity adjustments and requires large-scale investment decisions. Since these adjustments take place under uncertainty about the movements of the exchange rate, it is difficult to predict their future payoff. At the same time, such adjustments involve large costs, which may even increase with the rate at which they take place. The upshot is that firms in the export sectors need to decide not only whether and to what extent to alter their production scale but also at what time and for which horizons to take their decisions. If exchange rate movements are close to firms' previous forecasts, little adjustment may be needed. If the exchange rate moves in unforeseen directions, however, then firms will react by changing their production capacities and carrying out the necessary investments; they may even move their production abroad, as Japanese and German car makers demonstrated during the period considered here. There are good reasons that the adjustments will be gradual rather than abrupt. First, it may pay off for firms not to precipitate their actions but to act prudently and to wait and observe whether exchange rate movements turn out to be persistent. And as was already noticed, they may incur lower costs by carrying out changes in a smooth, rather than impatient, manner.

In summary, there are a variety of plausible explanations that can rationalize the pattern in which the current account adjusts in response to exchange rate movements. This paper does not take a definite view on which theoretical argument has the most merit. Instead, it has a more empirical focus as it primarily aims to characterize and examine the statistical link between exchange rate and current account movements.

\section{EMPIRICAL FRAMEWORK}

\subsection{Model}

In this section, a univariate Markov-switching time series model with timevarying probabilities is introduced, which makes it possible to analyse the recurrent trend reversals of the Japanese and German current account balances. The model helps to determine whether the occurrence of these reversals depends on, or is triggered by, the real exchange rate.

The current account is denoted as $z_{t}$ and its changes as $\hat{z}_{t}$, where $\hat{z}_{t}=(1-L) z_{t}$. The current account is modelled as an $\operatorname{ARIMA}(p, 1,0)$ process with a Markov-switching intercept: 


$$
\hat{z}_{t}=\alpha+\beta R_{t}+\phi_{1} \hat{z}_{t-1}+\ldots+\phi_{p} \hat{z}_{t-p}+\varepsilon_{t}, \quad t=1,2, \ldots, T
$$

where $\beta>0$ and $\varepsilon_{t} \sim \mathrm{N}\left(0, \sigma^{2}\right) . R_{t}$ is an unobserved random variable that takes the values 0 or 1 , depending on the current account's trend in a given period. For instance, with $\alpha<0$ and $\beta>0$, the current account is downward-trending if $R_{t}=0$ and upwardtrending if $R_{t}=1$. Suppose that regime 1 prevails whenever a latent variable, $R_{t}^{*}$, is positive, such that the probability of being in regime 1 is:

$$
\operatorname{Prob}\left(R_{t}=1\right)=\operatorname{Prob}\left(R_{t}^{*}>0\right)
$$

The latent variable, $R_{t}^{*}$, is determined by the following equation:

$$
R_{t}^{*}=\gamma_{0}\left(1-R_{t-1}\right)+\gamma_{1} R_{t-1}+\delta \check{q}_{t}+u_{t}
$$

where $u_{t} \sim \mathrm{N}(0,1)$. The variable $\check{q}_{t}$ is a measure of real exchange rate pressure, to be discussed below. Since in this specification $R_{t}^{*}$ depends on the lagged values of $R_{t}$, the transition probabilities of $R_{t}$ are time-varying and may be calculated as follows:

$$
\begin{aligned}
& \operatorname{Prob}\left(R_{t}=1 / R_{t-1}=1\right)=\operatorname{Prob}\left(R_{t}^{*}>0 / R_{t-1}=1\right) \\
& \quad=\operatorname{Prob}\left(\gamma_{1}+\delta \check{q}_{t}+u_{t}>0\right) \\
& \quad=\operatorname{Prob}\left(u_{t}>-\gamma_{1}-\delta \check{q}_{t}\right), \\
& \operatorname{Prob}\left(R_{t}=0 / R_{t-1}=0\right)=\operatorname{Prob}\left(R_{t}^{*} \leq 0 / R_{t-1}=0\right) \\
& \quad=\operatorname{Prob}\left(\gamma_{0}+\delta \check{q}_{t}+u_{t} \leq 0\right) \\
& =\operatorname{Prob}\left(u_{t} \leq-\gamma_{0}-\delta \check{q}_{t}\right) .
\end{aligned}
$$

Note that the transition probabilities depend on $\breve{q}_{t}$ and are therefore time-varying, except in the case in which $\delta=0$ when they become constant (the case of the standard Markov-switching model). Notice also that if $\delta<0$, a reversal of a current account that is worsening $\left(R_{t}=0\right)$ becomes more probable when the exchange rate is weak and competitive, whereas a rising current account $\left(R_{t}=1\right)$ is likely to start deteriorating when the exchange rate is strong or overvalued. 


\subsection{Variable selection}

To assess whether $\delta$ is nonzero, and therefore whether the exchange rate helps to predict current account reversals, I apply the variable selection methodology proposed by Geweke (1996) in the context of Bayesian regression analysis. The method assumes that the prior distribution of $\delta$ is a mixture of a - possibly truncatednormal and a discrete mass at zero. Let $d$ be an indicator variable taking the value 1 whenever $\delta$ is nonzero, then:

$$
\delta \begin{cases}=0 & \text { if } d=0, \\ \sim \mathrm{N}\left(\dot{\delta}, \dot{\omega}^{2}\right)_{[\llbracket \lambda<\delta<v]} & \text { if } d=1,\end{cases}
$$

where I[ $\cdot]$ refers to an indicator function that serves to truncate the normal prior for $\delta$ at $\lambda$ and at $v$. Since it is reasonable to assume here that $\delta \leq 0$, let $\lambda=-\infty$ and $v=0$.

Now let $\dot{p}$ denote the prior probability that $d$ is 1 and let $\bar{p}$ denote the corresponding posterior probability. Then $\bar{p}$ tells us the probability that the exchange rate is useful in explaining the probability of different regimes and should be retained in the model. Appendix B describes how $\bar{p}$ is calculated.

The issue of time-varying transition probabilities has been examined by a number of studies in the context of business cycles (see for instance Filardo and Gordon, 1998). The analysis in this paper has been inspired by the study of Kim and Nelson (1998) who test whether during a business cycle, the probability that a boom or recession comes to an end depends on the time it has persisted already.

\subsection{Inference}

Bayesian estimation of the model proceeds via the Gibbs sampler. The details are deferred to appendix A. Appendix B describes how $\bar{p}$ can be calculated from the information delivered by the Gibbs simulations. 


\section{Data and Specification of Priors}

\subsection{Data}

The data for Japan are taken from the International Financial Statistics of the IMF. A WPI-based real exchange rate is used in the estimations. The current account of Japan is seasonally adjusted using a centered, yearly moving average. The sample period of the Japanese data is from 1978Q4 to 1998Q2. The data for Germany are taken from the Economic Outlook of the OECD. The German current account is seasonally adjusted using a centered, 12-month moving average. The sample period of the German data is from 1979M12 to 1989M9.

\subsection{Defining exchange rate pressure}

As mentioned in the introduction, many authors belief that large movements of the real exchange rate do have impact on the trade balance but that the adjustment may take some time (see for instance Krugman, 1991). In assessing how the exchange rate affects their competitiveness, exporters and importers compare the most recent level of the exchange rate with the exchange rate they were adjusting to over recent years. In this model, the measure of exchange rate pressure, $\breve{q}_{t}$, is defined as the log of the ratio between the average real exchange rate during the previous year and the average real exchange rate during the previous three years:

$$
\check{q}_{t}=\frac{1}{k+1} \sum_{i=0}^{k} q_{t-\mathrm{i}}-\frac{1}{l+1} \sum_{i=0}^{l} q_{t-i},
$$

where

$$
\begin{aligned}
& k= \begin{cases}3 & \text { for quarterly data (Japan), } \\
11 & \text { for monthly data (Germany), }\end{cases} \\
& l= \begin{cases}11 & \text { for quarterly data (Japan), } \\
35 & \text { for monthly data (Germany) }\end{cases}
\end{aligned}
$$


The definition of $\check{q}_{t}$ is simple and intuitive and makes it easy to interpret the empirical results.

\subsection{Choice of priors}

In general, non-informative priors were adopted in the estimation of the model. This is true in particular for the parameter $\delta$, for which the prior parameterization $\dot{\delta}=0$ and $\dot{\omega}^{2}=10^{6}$ was chosen, see equation (6). One might want to set $\dot{p}$, the prior probability that $d=1$, to 0.5 or even higher, given the general belief that real exchange rates matter for the current account. However, to ensure that this assumption does not drive the results, the estimations were carried out with three alternative priors for $\dot{p}$, namely $0.25,0.5$ and 0.75 .

\section{Estimation}

\subsection{Estimation results}

This section discusses the estimation results. The empirical findings for the two countries are quite similar and shall therefore be presented jointly.

Consider first the summary statistics for the simulated parameter posteriors of the Gibbs sampler, which are given in tables 1 and 2. Two things are worth noting: First, the parameters $\alpha$ and $\beta$ are, respectively, negative and positive. The regime variable therefore distinguishes whether the current account is trending downwards or upwards. Second, $\delta$ has the expected (negative) sign. An appreciated currency will therefore tend to force the current account to weaken, and vice versa.

Since the Gibbs sampling scheme simulates the time series of the regime variable during each iteration, it is possible to estimate the evolution of regimes by averaging over the simulations. Figures 5 and 6 depict the estimated regimes for Japan and Germany, respectively. Also shown are the time series of the current accounts of both countries (seasonally adjusted, as used in the estimations). In both figures, the periods of each of the two regimes, 0 and 1, are well identified. 
Table 1. Parameter estimates for Japan. Mean, median and $90 \%$ interval of the simulated parameter posteriors

\begin{tabular}{cccc}
\hline & \multicolumn{3}{c}{ Posterior } \\
\cline { 2 - 4 } Parameter & Mean & Median & $90 \%$ interval \\
\hline$\alpha$ & -0.075593 & -0.076182 & $-0.10439,-0.046257$ \\
$\beta$ & 0.19047 & 0.19263 & $0.13692,0.23745$ \\
$\phi_{1}$ & 0.69158 & 0.68348 & $0.51268,0.88568$ \\
$\phi_{2}$ & 0.032266 & 0.035050 & $-0.18404,0.24281$ \\
$\phi_{3}$ & -0.30266 & -0.30395 & $-0.44706,-0.15467$ \\
$\sigma^{2}$ & 0.0053193 & 0.0051891 & $0.0038878,0.0071858$ \\
$\gamma_{0}$ & -1.2197 & -1.2186 & $-1.8556,-0.58558$ \\
$\gamma_{1}$ & 1.5887 & 1.6042 & $0.91211,2.2351$ \\
$\delta$ & -7.8497 & -8.5782 & $-14.007,0.00000$ \\
\hline
\end{tabular}

The top panels of figures 7 and 8 plot the estimated probabilities that a particular regime will persist, that is, $\operatorname{Prob}\left(R_{t}=0 / R_{t-1}=0\right)$ and $\operatorname{Prob}\left(R_{t}=1 / R_{t-1}=1\right)$. The transition probabilities for the regimes are easily calculated as one minus the plotted probabilities. Note that if $\delta$ was zero, the transition probabilities would be constant. However, the estimated transition probabilities in figures 7 and 8 are clearly timevarying. This is due to the fact that the exchange rate does play a role in determining the trends and occasional reversals of the current account in both countries.

The lower panels of figures 7 and 8 plot for each period the expected regime duration that would result if the transition probability prevailing in the particular period would remain at its present level. The graphs suggest that when the exchange rate is favourable to the prevailing trend of the current account, the trend may be expected to last very long, provided the exchange rate remains unaltered.

\subsection{Significance of the exchange rate}

Table 3 presents the posterior estimates of $\bar{p}$, the probability that $d=1$, under different assumptions about the prior probability, $\dot{p}$. Both for Japan and Germany, there appears to be strong evidence in favour of including $\check{q}_{t}$, the measure of exchange rate pressure, into the latent variable regression in equation (3). 
Table 2. Parameter estimates for Germany. Mean, median and $90 \%$ interval of the simulated parameter posteriors

\begin{tabular}{cccc}
\hline & \multicolumn{3}{c}{ Posterior } \\
\cline { 2 - 4 } Parameter & Mean & Median & $90 \%$ interval \\
\hline$\alpha$ & -28.814 & -33.680 & $-76.491,40.002$ \\
$\beta$ & 378.55 & 403.33 & $146.69,490.36$ \\
$\phi_{1}$ & -0.25651 & -0.28727 & $-0.45136,0.071705$ \\
$\phi_{2}$ & 0.097839 & 0.079024 & $-0.061187,0.32538$ \\
$\phi_{3}$ & -0.23256 & -0.24443 & $-0.39510,-0.031404$ \\
$\phi_{4}$ & -0.40391 & -0.42418 & $-0.59101,-0.13973$ \\
$\sigma^{2}$ & 24779. & 23058. & $17343 ., 39487$. \\
$\gamma_{0}$ & -1.2219 & -1.2669 & $-1.8451,-0.38496$ \\
$\gamma_{1}$ & 0.92031 & 1.1187 & $-0.84297,1.6821$ \\
$\delta$ & -15.000 & -11.806 & $-43.148,-1.0441$ \\
\hline
\end{tabular}

\section{Conclusion}

This paper applies a Markov-switching time series model with time-varying probabilities to the current account balances of Japan and Germany. The current account is subject to occasional trend reversals whose probability is assumed to depend, among other things, on the level of the exchange rate. It is shown that Bayesian inference is feasible via a Gibbs sampling scheme. A variable selection procedure is used to investigate whether the real exchange rate helps to explain the occurrence of current account reversals.

Table 3. Posterior probabilities that $d=1$ (Japan and Germany). Posterior probabilities $\bar{p}$ that $d=1$, using different priors, $\dot{p}$, for Japanese and German data

\begin{tabular}{|c|c|}
\hline \multicolumn{2}{|c|}{ Japan: $\operatorname{Prob}(d=1)$} \\
\hline Prior: $\dot{p}$ & Posterior: $\bar{p}$ \\
\hline 0.25 & 0.84840 \\
\hline 0.5 & 0.86760 \\
\hline 0.75 & 0.87920 \\
\hline
\end{tabular}

\begin{tabular}{|c|c|}
\hline \multicolumn{2}{|c|}{ Germany: $\operatorname{Prob}(d=1)$} \\
\hline Prior: $\dot{p}$ & Posterior: $\bar{p}$ \\
\hline 0.25 & 0.95120 \\
\hline 0.5 & 0.96040 \\
\hline 0.75 & 0.96760 \\
\hline
\end{tabular}


Figure 5. Regime probabilities (Japan). Top: Japanese current account (seasonally adjusted). Bottom: mean posterior probabilities of the Japanese current account being in regime 1 , that is, $\operatorname{Prob}\left(R_{t}=1\right)$

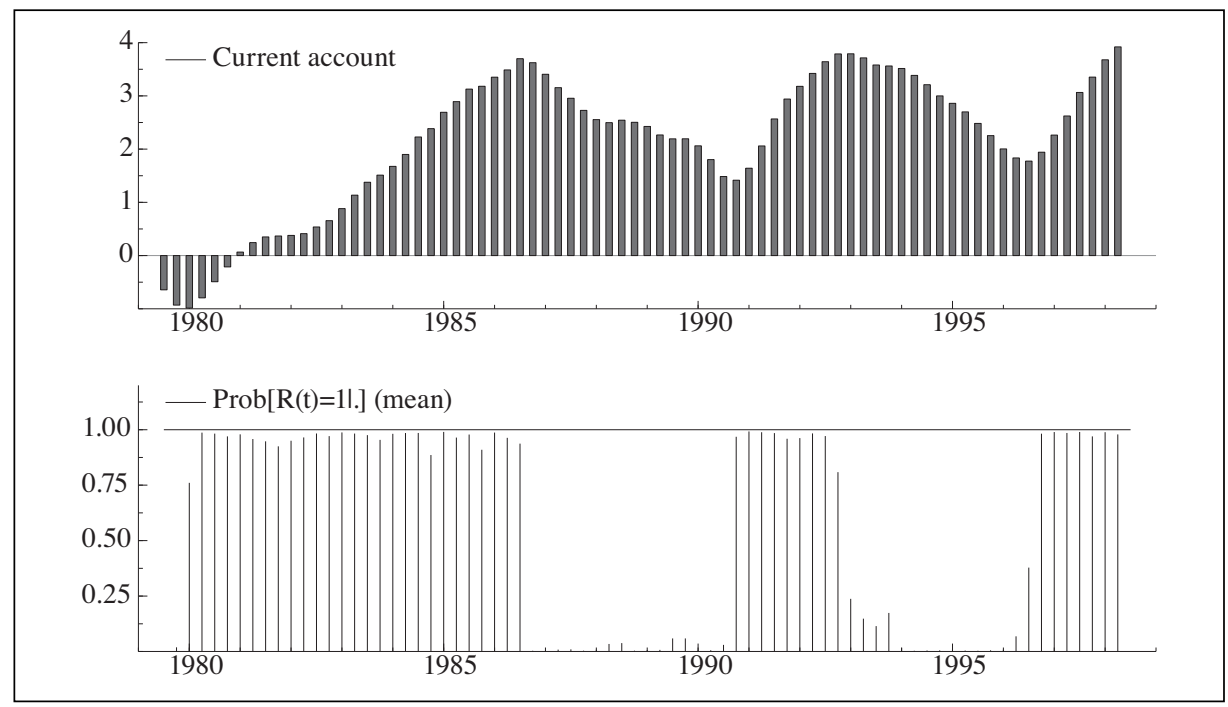

The paper finds strong evidence of recurrent current account reversals, both in Japan and Germany. For each period, it presents posterior estimates of the probability that the current account is in a particular regime (boom or decline) as well as of the time-varying probability that the current account will stay in that regime. The hypothesis that the real exchange rate can explain the occurrence of current account reversals is also supported by data. This result is robust to assumptions about priors and other aspects of the model.

This paper offers a novel perspective regarding the impact of the exchange rate on the current account. Underlying the empirical model in this paper is the idea that exchange rate movements can lead to trend reversals of the current account in situations when they move too far away from their trend. In comparison, marginal changes in the exchange rate induce only minor adjustments. The paper's message therefore is that exchange rates only hurt when they move too strongly into the wrong direction.

The paper may thus help to explain why empirical researchers have found it difficult to come up with reasonably large - or indeed correctly-signed - estimates for the sensitivity of trade flows to exchange rate movements. An interesting aspect of the setup used here is that even though the current account and the exchange rate 
Figure 6. Regime probabilities (Germany) Top: German current account (seasonally adjusted, in millions of German mark). Bottom: mean posterior probabilities of the German current account being in regime 1, that is, $\operatorname{Prob}\left(R_{t}=1\right)$

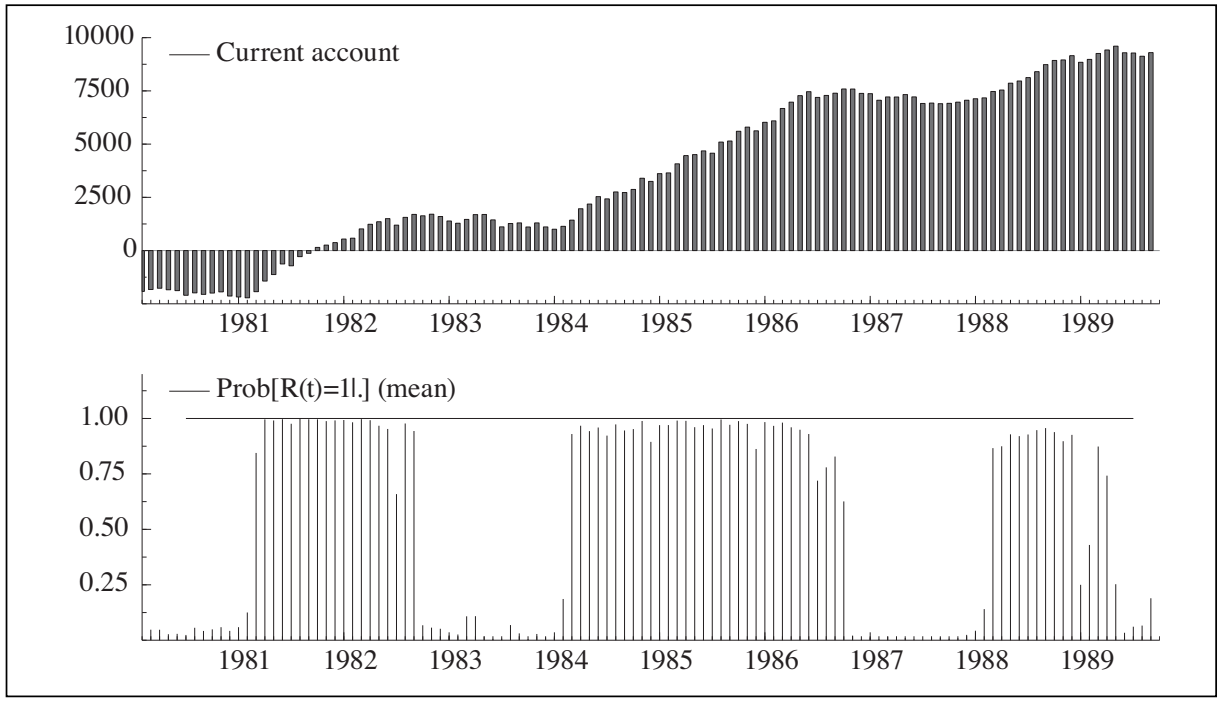

are not independent, neither the level of the current account nor its changes need to be correlated with the exchange rate at all.

Further theoretical research would be desirable to better understand the apparent persistence of current account reversals that are set into motion by exchange rate fluctuations. Another interesting topic for future research is the possibility of a dynamic feedback from the current account to the exchange rate, for which there seems to be evidence both in the Japanese and German data (Müller-Plantenberg, 2006).

\section{Appendix A. Bayesian Estimation}

This appendix outlines the estimation and variable selection procedures proposed by Kim and Nelson (1998) and Geweke (1996) and shows how they can be applied to the economic question of this paper. 
Figure 7. Time-varying transition probabilities (Japan). Top panel: transition probabilities, $\operatorname{Prob}\left(R_{t}=0 / R_{t-1}=0\right)$ and $\operatorname{Prob}\left(R_{t}=1 / R_{t-1}=1\right)$, for Japan (for quarterly data). Bottom panel: expected duration of regime 0 and 1 (in quarters), computed from the transition probability in each period, on the assumption that the determinants of the transition probability remain unchanged

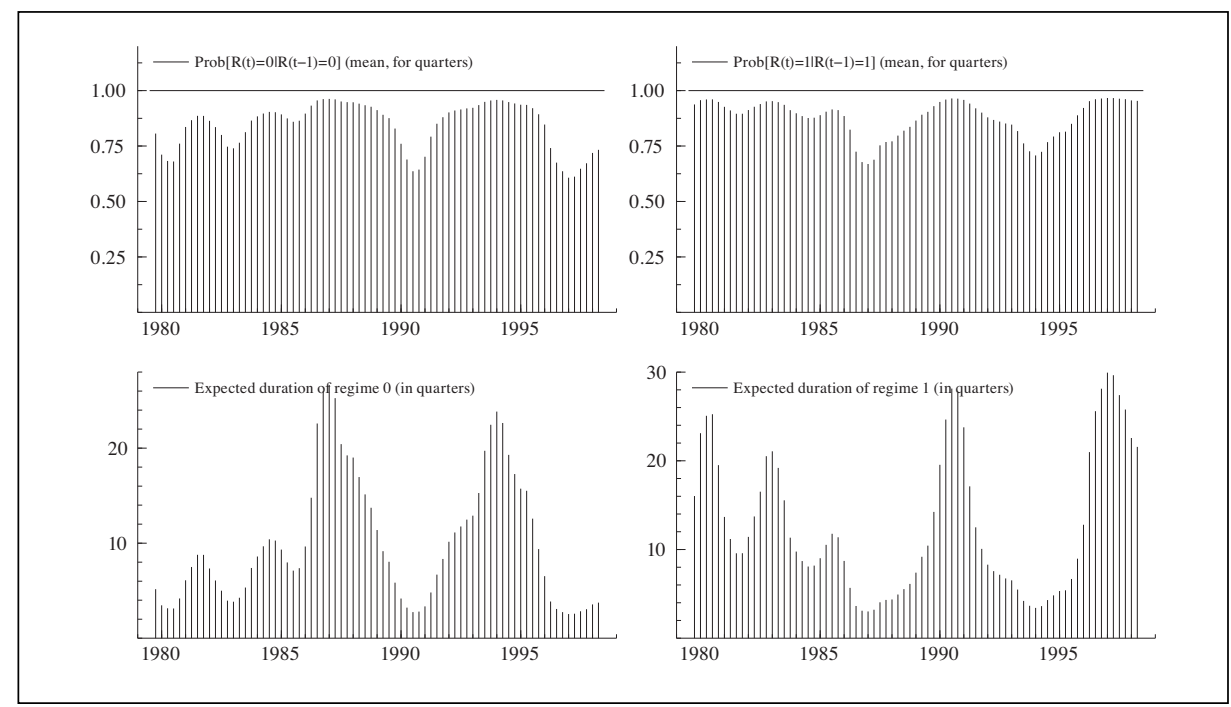

\section{A.1. Gibbs sampling}

To carry out Bayesian inference on the model, the simulation tool of Gibbs sampling is used. For an introduction to MCMC methods and the Gibbs sampler, see for example Gelman et al. (1995) and Kim and Nelson (1999).

The objective is to find a complete set of conditional distributions of all the parameters, on which the Gibbs sampling scheme can be run. It turns out that this task is facilitated once we treat the regimes, $\left\{R_{1}, R_{2}, \ldots, R_{T}\right\}$, as well as the latent regimes, $\left\{R_{1}{ }^{*}, R_{2}{ }^{*}, \ldots, R_{T}^{*}\right\}$, as additional unknown parameters and analyse them jointly with other parameters (Albert and Chib, 1993). Given the regimes and latent regimes, conditional inference on all other parameters amounts to the estimation of the parameters of two independent regression equations. Given the parameters, however, procedures are available that enable us to retrieve the conditional distribution of $\left\{R_{1}, R_{2}, \ldots, R_{T}\right\}$ and $\left\{R_{1}^{*}, R_{2}^{*}, \ldots, R_{T}^{*}\right\}$. 
Figure 8. Time-varying transition probabilities (Germany). Top panel: transition probabilities, $\operatorname{Prob}\left(R_{t}=0 / R_{t-1}=0\right)$ and $\operatorname{Prob}\left(R_{t}=1 / R_{t-1}=1\right)$, for Germany; calculated for quarters rather than months to facilitate comparison with the corresponding probabilities for Japan. Bottom panel: expected duration of regime 0 and 1 (in quarters), computed from the transition probability of each period, on the assumption that the determinants of the transition probability remain unchanged

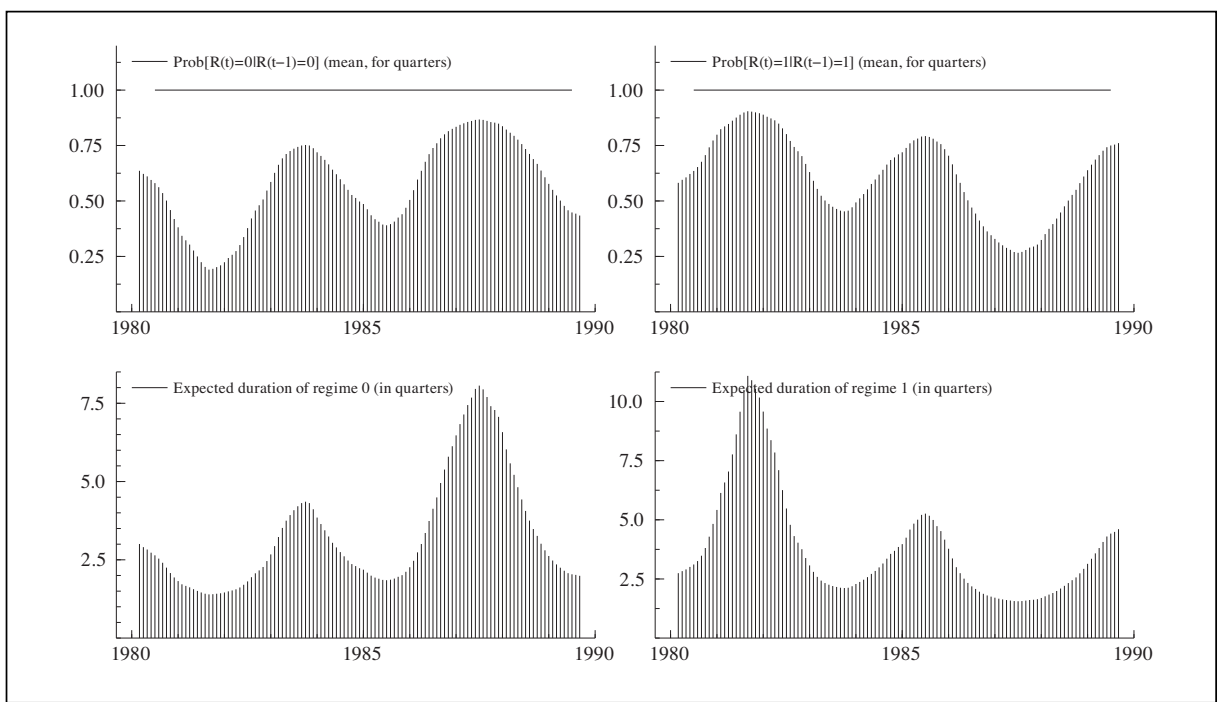

\section{A.2. Conditional structure of the model}

For use below, define $\tilde{\hat{z}}:=\left[\begin{array}{llll}\hat{z}_{1}, & \hat{z}_{2}, \ldots, \hat{z}_{T}\end{array}\right]^{\prime}, \quad \tilde{R}_{T}:=\left[\begin{array}{lll}R_{1}, & R_{2}, \ldots, R_{T}\end{array}\right]^{\prime}$ and $\tilde{R}_{T}{ }^{*}:=\left[R_{1}{ }^{*}, R_{2}{ }^{*}, \ldots, R_{\mathrm{T}}{ }^{*}\right]^{\prime}$ and let $\phi:=\left[\phi_{1}, \phi_{2}, \ldots, \phi_{p}\right]^{\prime}$. To allow for general applicability, it is from now on assumed that, apart from the lagged regimes, there are $m$ variables in the latent regime equation (3), denoted $\check{q}_{i t}, i=1,2, \ldots, m$. Define the $T$ x $m$ data matrix $\tilde{\check{q}}_{T}:=\left[\check{q}_{i t}\right]^{\prime}$.

The conditional distributions that form the basis of the simulation are given by:

- $\alpha, \beta \mid \tilde{\hat{z}}_{T}, \tilde{R}_{T}, \phi, \sigma^{2}$

- $\sigma^{2} \mid \tilde{\hat{z}}_{T}, \tilde{R}_{T}, \alpha, \beta, \phi$

- $\phi \mid \tilde{\hat{z}}_{T}, \tilde{R}_{T}, \alpha, \beta, \sigma^{2}$

- $R_{t} \mid \tilde{R}_{-t}, \tilde{\hat{z}}_{T}, \tilde{R}_{T}^{*}, \tilde{q}_{T}, \alpha, \beta, \phi, \sigma^{2}, \gamma_{0}, \gamma_{1}, \delta_{i}, \quad t=1,2, \ldots, T$

- $\tilde{R}_{T}^{*} \mid \tilde{R}_{T}, \tilde{q}_{T}, \gamma_{0}, \gamma_{1}, \delta_{i}$ 
- $\gamma_{0}, \gamma_{1} \mid \tilde{R}_{T}^{*}, \tilde{q}_{T}, \delta_{i}$

- $\delta_{i} \mid \tilde{R}_{T}^{*}, \tilde{q}_{T}, \gamma_{0}, \gamma_{1}, \delta_{j \neq i}$

where $\tilde{R}_{-t}:=\left[R_{1}, R_{2}, \ldots, R_{t-1}, R_{t+1}, \ldots, R_{T}\right]$ '. Each of these complete conditionals can be simulated, thus leading, via the Gibbs sampler, to a posterior sample from the joint distribution of the parameters, the regimes and the latent regimes.

The Gibbs sampler converges rapidly and is run with 4500 iterations, the initial half of which are discarded.

\section{A.3. Simulation of parameters and regimes}

Generating $\alpha$ and $\beta$. The parameters $\alpha$ and $\beta$ are generated conditional on $\tilde{\hat{z}}_{T}$, $\tilde{R}_{T}, \phi, \sigma^{2}$. Consider the following regression:

$$
\phi(L) \hat{z}_{t}=\alpha+\beta R_{t}+\varepsilon_{t}, \quad t=1,2, \ldots, T,
$$

where $\phi(L):=1-\phi_{1} L-\ldots-\phi_{p} L^{p}$. Define the matrices $\tilde{Y}_{1}$ and $\tilde{X}_{1}$ as the matrices of the left-hand-side and the right-hand-side variables of this regression, respectively. Let $\theta:=[\alpha, \beta]$, and let us adopt a normally distributed prior, $\theta \sim \mathrm{N}(\dot{\theta}, \dot{\Theta})$, where $\dot{\Theta}$ is a diagonal matrix. The posterior is then given by:

$$
\theta \mid \tilde{\hat{z}}_{T}, \tilde{R}_{T}, \phi, \sigma^{2} \sim \mathrm{N}(\bar{\theta}, \bar{\Theta}),
$$

where $\bar{\Theta}=\left(\dot{\Theta}^{-1}+\sigma^{-2} \tilde{X}_{1}^{\prime} \tilde{X}_{1}\right)^{-1}$ and $\bar{\theta}=\bar{\Theta}\left(\dot{\Theta}^{-1} \dot{\theta}+\sigma^{-2} \tilde{X}_{1}^{\prime} \tilde{Y}_{1}\right)$.

Generating $\sigma^{2}$. To generate $\sigma^{2}$ conditional on $\tilde{\hat{z}}_{T}, \tilde{R}_{T}, \alpha$ and $\beta$, the following prior is employed:

$$
\sigma^{2} \sim \mathrm{IG}\left(\frac{\dot{v}_{1}}{2}, \frac{\dot{v}_{2}}{2}\right),
$$

where IG refers to the inverted Gamma distribution and $\dot{v}_{1}$ and $\dot{v}_{2}$ are appropriately chosen (here $\dot{v}_{1}$ and $\dot{v}_{2}$ are both set to zero, implying a non-informative prior). The posterior is then given by: 


$$
\sigma^{2} \mathrm{I} \tilde{\hat{z}}_{T}, \tilde{R}_{T}, \alpha, \beta \sim \mathrm{IG}\left(\frac{\hat{v}_{1}}{2}, \frac{\hat{v}_{2}}{2}\right)
$$

where $\hat{v}_{1}=\dot{v}_{1}+T$ and $\hat{v}_{2}=\dot{v}_{2}+\left(\tilde{Y}_{1}-\tilde{X}_{1} \theta\right)^{\prime}\left(\tilde{Y}_{1}-\tilde{X}_{1} \theta\right)$.

Generating $\phi$. The parameters $\phi_{1}, \ldots, \phi_{p}$ are generated conditional on $\tilde{\hat{z}}_{T}, \tilde{R}_{T}, \alpha$, $\beta, \sigma^{2}$. Consider the following regression:

$$
\tilde{z}_{T}-\alpha-\beta R_{t}=\phi_{1} \tilde{z}_{t-1}+\ldots+\phi_{p} \tilde{z}_{t-p}+\varepsilon_{t}, \quad t=1,2, \ldots, T .
$$

Define the matrices $\tilde{Y}_{2}$ and $\tilde{X}_{2}$ as the matrices of the left-hand-side and the righthand-side variables of this regression, respectively. Let us adopt a normally distributed prior, $\phi \sim \mathrm{N}(\dot{\phi}, \dot{\Phi})$, where $\Phi$ is a diagonal matrix. The posterior is then given by:

$$
\phi \sim \mathrm{N}(\bar{\phi}, \bar{\Phi})_{[[s(\phi)]}
$$

where $\left(\bar{\Phi}=\dot{\Phi}^{-1}+\sigma^{-2} \tilde{X}_{2}^{\prime} \tilde{X}_{2}\right)^{-1}, \bar{\phi}=\bar{\Phi}\left(\dot{\Phi}^{-1} \dot{\phi}+\sigma^{-2} \tilde{X}_{2}^{\prime} \tilde{Y}_{2}\right)$ and $\mathrm{I}[s(\phi)]$ is an indicator function used to denote that the roots of $\phi(L)$ lie outside the unit circle.

Generating $\tilde{R}_{T}$ The regimes $R_{t}, t=1,2, \ldots, T$, are generated one at a time, where use is made of the single-move Gibbs sampling procedure suggested by Albert and Chib (1993).

Generating $\tilde{R}_{T}^{*} \quad$ Once simulated values of $\tilde{R}_{T}$ are obtained, it is straightforward to generate $R_{t}^{*}, t=1,2, \ldots, T$, from equation (3):

$$
R_{t}^{*} \sim \begin{cases}\mathrm{N}\left(\gamma_{0}\left(1-R_{t-1}\right)+\gamma_{1} R_{t-1}+\sum_{i} \delta_{i} \check{q}_{i t}, 1\right)_{\mathrm{I}\left(R_{t}^{*}>0\right)} & \text { if } R_{t}=1, \\ \mathrm{~N}\left(\gamma_{0}\left(1-R_{t-1}\right)+\gamma_{1} R_{t-1}+\sum_{i} \delta_{i} \check{q}_{i t}, 1\right)_{\mathrm{I}\left(R_{t}^{*} \leq 0\right)} & \text { if } R_{t}=0 .\end{cases}
$$

Note that the simulation of $\tilde{R}_{T}^{*}$ enables us to analyse the conditional distributions of the parameters of equation (3). By artificially generating data for the latent variable, we are applying the idea of data augmentation as originally proposed by Tanner and Wong (1987). 
Generating $\gamma$ The parameters $\gamma_{0}$ and $\gamma_{1}$ are generated conditional on $\tilde{R}_{T}^{*}, \check{q}_{T}$ and $\delta_{i}$. Consider the following regression:

$$
R_{T}^{*}-\sum_{i} \delta_{i} \check{q}_{i t}=\gamma_{0}\left(1-R_{t-1}\right)+\gamma_{1} R_{t-1}+u_{t}
$$

Define the matrices $\tilde{Y}_{3}$ and $\tilde{X}_{3}$ as the matrices of the left-hand-side and the righthand-side variables of this regression, respectively. Let $\gamma:=\left[\gamma_{0}, \gamma_{1}\right]^{\prime}$, and let us adopt a normally distributed prior, $\gamma \sim \mathrm{N}(\dot{\gamma}, \dot{\Gamma})$, where $\dot{\Gamma}$ is a diagonal matrix. The posterior is then given by:

$$
\gamma \mid \tilde{R}_{T}^{*}, \check{q}_{T}, \delta_{i} \sim \mathrm{N}(\bar{\gamma}, \bar{\Gamma}),
$$

where $\bar{\Gamma}=\left(\dot{\Gamma}^{-1}+\tilde{X}_{3}^{\prime} \tilde{X}_{3}\right)^{-1}$ and $\bar{\gamma}=\bar{\Gamma}\left(\bar{\Gamma}^{-1} \dot{\gamma}+\tilde{X}_{3}^{\prime} \tilde{Y}_{3}\right)$.

Generating $\delta_{i} \quad$ For each $i \in\{1,2, \ldots, m\}, \delta_{i}=0$ if $d_{i}=0$. If $d_{i} \neq 0$, the generation of $\delta_{i}$, conditional on $\tilde{R}_{T}^{*}, \tilde{q}_{T}, \gamma_{0}, \delta_{j \neq i}$, proceeds as follows. Consider the regression:

$$
R_{T}^{*}-\gamma_{0}\left(1-R_{t-1}\right)-\gamma_{1} R_{t-1}-\sum_{j \neq i} \delta_{j} \check{q}_{j \neq i, t}=\delta_{i} \check{q}_{i t}+u_{t}
$$

Define the matrices $\tilde{Y}_{4}$ and $\tilde{X}_{4}$ as the matrices of the left-hand-side and the righthand-side variables of this regression, respectively. Consider the prior

$$
\delta_{i} \sim \mathrm{N}\left(\dot{\delta}_{i}, \dot{\omega}_{i}^{2}\right)_{\mathrm{I}\left[\lambda_{i}<\delta_{i}<v_{i}\right]}
$$

where $\mathrm{I}[\cdot]$ refers to an indicator function allowing for the possibility of a truncated normal prior. The posterior is then given by:

$$
\delta_{i} \mid \tilde{R}_{T}^{*}, \tilde{q}_{T}, \gamma, \delta_{j \neq i} \sim \mathrm{N}\left(\bar{\delta}_{i}, \bar{\omega}_{i}^{2}\right)_{\mathrm{I}\left[\lambda_{i}<\delta_{i}<v_{i}\right]},
$$

where $\bar{\omega}_{i}^{2}=\left(\dot{\omega}_{i}^{-2}+\tilde{X}_{4}{ }^{\prime} \tilde{X}_{4}\right)^{-1}$ and $\bar{\delta}_{i}=\bar{\omega}_{i}^{2}\left(\dot{\omega}_{i}^{-2} \dot{\delta}_{i}+\tilde{X}_{4}{ }^{\prime} \tilde{Y}_{4}\right)$. Notice that the truncation of the prior carries over to the posterior. 


\section{Appendix B. Variable Selection in Latent Regime Equation}

This section describes how the variable selection procedure of Geweke (1996) is employed in this paper. Recall that in equation (3), a variable $\breve{q}_{i}, i \in\{1,2, \ldots, m\}$, is retained if and only if $d_{i}=1$; otherwise it is excluded from the model. This suggests carrying out the following procedure during each iteration of the Gibbs sampler, consecutively for each $i \in\{1,2, \ldots, m\}$ : First, evaluate $\bar{p}_{i}$, the conditional posterior probability that $d_{i}=1$. Then, based on a comparison of $\bar{p}_{i}$ with a drawing from the uniform distribution, set $d_{i}$ to 1 or 0 .

Let $\mathrm{BF}_{i}$ denote the conditional Bayes factor in favour of $d_{i}=1$ versus $d_{i}=0$, conditional on the other parameters of the model, and recall that $\dot{p}_{i}$ is the prior probability that $d_{i}=1$. As shown in Geweke (1996), $\bar{p}_{i}$ can be calculated as follows:

$$
\bar{p}_{i}=\frac{\dot{p}_{i} \times \mathrm{BF}}{\left(1-\dot{p}_{i}\right)+\dot{p}_{i} \times \mathrm{BF}},
$$

The conditional Bayes factor in favour of $d_{i}=1$ versus $d_{i}=0$ is given by:

$$
\begin{aligned}
\mathrm{BF}= & \exp \left(\frac{\bar{\delta}_{i}^{2}}{2 \dot{\omega}_{i}^{2}}-\frac{\dot{\delta}_{i}^{2}}{2 \dot{\omega}_{i}^{2}}\right) \frac{\bar{\omega}_{i}}{\dot{\omega}_{i}} \\
& \mathrm{x}\left[\Phi\left(\frac{v_{i}-\bar{\delta}_{i}}{\bar{\omega}_{i}}\right)-\Phi\left(\frac{\lambda_{i}-\bar{\delta}_{i}}{\bar{\omega}_{i}}\right)\right] \\
& \mathrm{x}\left[\Phi\left(\frac{v_{i}-\dot{\delta}_{i}}{\dot{\omega}_{i}}\right)-\Phi\left(\frac{\lambda_{i}-\dot{\delta}_{i}}{\dot{\omega}_{i}}\right)\right]^{-1},
\end{aligned}
$$

where $\Phi(\cdot)$ denotes the cdf of the normal distribution.

\section{REFERENCES}

Albert, J. H. and S. Chiв (1993, January). Bayes inference via Gibbs sampling of autoregressive time series subject to Markov mean and variance shifts. Journal of Business and Economic Statistics 11(1), 1-15. 
BaLDwIN, R. E. (1988). Hysteresis in import prices: The beachhead effect. American Economic Review 78(4), 773-785.

Baldwin, R. E. and P. R. Krugman (1989, November). Persistent trade effects of large exchange rate shocks. Quarterly Journal of Economics 104(4), 635-654.

Dixit, A. K. and R. S. Pindyck (1994). Investment under Uncertainty. Princeton, New Jersey: Princeton University Press.

Filardo, A. J. and D. B. Gordon (1998). Business cycle durations. Journal of Econometrics 85, 99-123.

Gelman, A., J. B. Carlin, H. S. Stern, and D. B. Rubin (1995). Bayesian Data Analysis. London: Chapman and Hall.

GEWEKE, J. (1996). Variable selection and model comparison in regression. In J. O. Berger, J. M. Bernardo, A. P. Dawid, A. F. M. Smith, et al. (Eds.), Proceedings on the Fifth Valencia International Meeting on Bayesian Statistics. Oxford: Oxford University Press.

Kim, C.-J. and C. R. Nelson (1998, May). Business cycle turning points, a new coincident index, and tests of duration dependence based on a dynamic factor model with regimeswitching. Review of Economics and Statistics 80(2), 188-201.

- (1999). State-Space Models with Regime Switching: Classical and Gibbs-Sampling Approaches with Applications. Cambridge, Mass.: MIT Press.

КІм, С. K. (1998, March). Exchange rate variations and the trade structure in the Federal Republic of Germany. Jahrbücher für Nationalökonomie und Statistik 217(2), 161-184.

Krugman, P. R. (1991). Has the adjustment process worked? In C. F. Bergsten (Ed.), International Adjustment and Financing. Washington, DC: Institute for International Economics.

Müller-Plantenberg, N. (2006). Japan's imbalance of payments. In M. M. Hutchison and F. Westermann (Eds.), Japan's Great Stagnation: Financial and Monetary Policy Lessons for Advanced Economies. MIT Press.

Rose, A. K. (1990, November). Exchange rates and the trade balance: Some evidence from developing countries. Economics Letters 34(3), 271-275.

SAwyer, W. C. and R. L. Sprinkle (1997, June). The demand for imports and exports in Japan: a survey. Journal of the Japanese and International Economies 11(2), 247-259.

TANnER, M. A. and W. H. Wong (1987, June). The calculation of posterior densities by data augmentation. Journal of the American Statistical Association 82(398), 528-540. 